\title{
DEBATE
}

\section{Does increased aromatase activity in adipose fibroblasts cause low sexual desire in patients with HIV lipodystrophy?}

\author{
D Goldmeier, G Scullard, M Kapembwa, H Lamba, G Frize
}

Sex Transm Inf 2002;78:64-66

There is evidence from our own unit and other workers that many patients who have lipodystrophy on HAART given for HIV disease also have raised oestrogen levels and complain of low sexual desire. This hypothesis paper discusses a possible pathological mechanism for these changes - an increase in the number of fibroblasts and macrophages present in lipoatrophic areas that could convert testosterone to oestrogen by intracellular aromatisation. This process is known to be enhanced by increased levels of tumour necrosis factor, interleukin 6 (IL-6), and hydroxycorticosteroids present in many patients with HIV lipodystrophy. Treatment options are discussed, including aromatase inhibitors and testosterone.

See end of article for authors' affiliations

Correspondence to: Dr Goldmeier, Jefferiss Wing, St Mary's Hospital, London W2 INY, UK

Accepted for publication 28 November 2001
S exual dysfunction affects $31 \%$ of men aged 18-59 years selected at random from the general population of the United States. Of those with any problems, $10 \%$ have erectile dysfunction, $30 \%$ premature ejaculation, $8 \%$ delayed orgasm, and 15\% low sexual desire. ${ }^{1}$

Little, however, is known about the rate of sexual dysfunction in HIV positive men, particularly those on highly active antiretroviral therapy (HAART), although biased samples of such men suggest a spectrum of sexual problems similar to the general population. ${ }^{2}$ Most of these available data on patients with HIV are among homosexual men, whereas non-biased sexual dysfunction data contain less than $5 \%$ of exclusively homosexual men. ${ }^{3}$ Be that as it may, biased samples of HIV positive men taking no specific antiretroviral treatment suggest that up to $55 \%$ complain of sexual problems. ${ }^{2}{ }^{4}$ HIV positive men with low sexual desire in the pre-HAART era were reported to have a significantly lower serum testosterone level than non-dysfunctional HIV comparisons. ${ }^{5}$ However, over half this "convenience sample" had a history of chemical dependency, including androgen use and abuse. None of the sample of 50 patients, however, had a raised oestrogen level. ${ }^{5}$ Other workers suggest that there appears to be a steady decline in testosterone levels with HIV disease progression. ${ }^{6}$

Other possible causes of sexual problems in HIV positive men include peripheral and autonomic neuropathy (caused by antiretrovirals and HIV itself), ${ }^{7-11}$ anxiety and depression, ${ }^{12}$ and other medications (for example, ketoconazole and tranquillisers $).{ }^{13}$
Since HAART has become widely available it is apparent that there is a new sexual dysfunction syndrome in men, involving low sexual desire, lipodystrophy, and raised serum oestrogen levels. Colebunders et al alluded to this in an early report, which pointed out that $4 \%$ of men on HAART, particularly protease inhibitor (PI) treatment, spontaneously complained of low sexual desire. ${ }^{14}$ However, results from an anonymous questionnaire given to 77 homosexual men from the same patient population suggested that $32(42 \%)$ had developed significant low desire since initiating treatment. ${ }^{14}$

A more recent, larger pan-European study would seem to confirm these rates-with 308 of $766(40 \%)$ patients on PIs having decreased sexual desire compared to 22 out of 138 (16\%) on a PI naive regimen. ${ }^{13}$

HAART, in particular a combination of nucleoside reverse transcriptase inhibitors and PIs, seems also to be associated with increased oestradiol levels in men. ${ }^{15}$ In our department 17 of 56 men seen consecutively with HIV lipodystrophy on HAART were found to have significantly raised oestrogen levels, and 13 of the 17 complained of low sexual desire. Conversely, we found that of the remaining 39 (of 56 patients) with normal oestrogen levels only two complained of low desire. Where testosterone levels were assayed in our patients (total testosterone) they have mostly been in the low normal range with the occasional low level.

Up to $80 \%$ of men on HAART may develop HIV lipodystrophy, ${ }^{16}{ }^{17}$ which usually presents as loss of adipose tissue from the limbs and face, and fatty deposition in the dorsocervical and omental areas. ${ }^{18}$ Other patients show only central fat accumulation or only peripheral fat loss. ${ }^{19}$ However, more recent prospective studies suggest lower rates for HAART related lipodystrophy of between $17 \%$ and $49 \% .^{20-22}$

In this paper, we suggest that HIV associated lipodystrophy may be a major direct contributor to raised oestrogen levels and hence cause low sexual desire. We hypothesise this is caused by peripheral aromatisation of androgens to oestrogens in the sites of pathological adipose tissue activity.

Abbreviations: HAART, highly active antiretroviral therapy; IL, interleukin; PI, protease inhibitors; SHBG, sex hormone binding globulin; TNF, tumour necrosis factor 


\section{AROMATASE ACTIVITY IN ADIPOSE TISSUE}

Aromatase is an enzyme present in many tissues, but particularly in adipose tissue. Specifically, this enzyme, aromatase cytochrome P450, is encoded by the CYP19 gene. ${ }^{23}$ This converts androgens to oestrone and oestradiol.

Adipose tissue contains adipocytes that carry the accumulated fat burden itself, as well as stromal cells, which are relatively thinly dispersed blood vessels and fibroblasts. It appears that $90 \%$ of the aromatase activity in fatty tissue is found in the stromal cells, particularly the fibroblasts, ${ }^{24}$ although some is also found in monocyte derived macrophages. ${ }^{25}$ Of some importance is the fact that the fractional conversion of androstenedione to oestrogens in obese subjects may not decrease after weight loss, probably because the number of stromal cells in the remaining adipose tissue does not appreciably decrease. ${ }^{24}{ }^{26}$ Furthermore, aromatase activity and its expression in adipose tissue is markedly potentiated by various promoters, ${ }^{27}$ as well as by the cytokine IL-6 and tumour necrosis factor (TNF).$^{28} 29$ Adipose stromal cells from omental fat, but not subcutaneous fat, have been shown to generate active cortisol from inactive glucocorticosteroids through the expression of the enzyme 11- $\beta$-hydroxy steroid dehydrogenase.$^{30}$ These active glucocorticoids further encourage aromatase activity. ${ }^{31}$ Other workers have shown that aromatase activity, at least in subcutaneous adipose tissue, is higher in men than women. ${ }^{32}$ The rate of conversion of testosterone to oestrogen in omental tissue appears to be slower than in other adipose tissue sites, although the final concentrations of oestrogens in both sites are similar. ${ }^{24}$

\section{LOW SEXUAL DESIRE IN HIV PATIENTS WITH LIPODYSTROPHY - THE AROMATASE FACTOR?}

Low sexual desire in men may be secondary to a low testosterone level. Although we found such low levels only occasionally in our patients on HAART, our laboratory estimated only total testosterone levels and sex hormone binding globulin ( SHBG) levels are currently not available to us. Other studies have, in fact, shown that patients with advanced HIV on or off HAART do have low free testosterone levels, but there is no difference in the mean values comparing the treated with the untreated..$^{33}$ There are a number of theoretical reasons why free testosterone might be lower in the patients on HAART. These include an increase in SHBG levels secondary to the raised oestrogen ${ }^{34}{ }^{35}$ levels themselves, via diminished gonadotrophin feedback, or because of a direct effect of the HAART therapy. ${ }^{32}$ Be that as it may, on laboratory results available to us we found significantly raised oestrogen but normal testosterone levels. Physiological concentrations of testosterone are measured in nanomoles, compared to picomoles for oestrogens. Therefore, molecule for molecule aromatisation will result in relatively little fall in testosterone compared to a proportionately high rise in oestrogens. Studies have demonstrated that such a chemical scenario is possible-that is, that high oestrogen levels in men do not necessarily result in a fall in androgen levels. ${ }^{36}{ }^{37}$ These high oestrogen levels, therefore, seem capable of decreasing sexual libido and lowering sexual activity. ${ }^{36}{ }^{37}$

There are a number of factors that seem to point to an increase in adipose based fibroblast/macrophage aromatase production in patients with HIV lipodystrophy. In a recent study, biopsy material from the subcutaneous tissue from the anterolateral aspect of the thighs of 14 men with HIV lipoatrophy showed no acute inflammation, but did show an increase in lipogranulomas and vascular proliferation in all 14 men. ${ }^{38}$ Lipogranulomas are pathological. They consist of areas of infiltration by chronic inflammatory cells such as fibroblasts and tissue macrophages (Rob Goldin, personal communication). We postulate therefore that in HIV lipodystrophy there is a total increased fibroblast burden by nature of both the laying down of new fat in areas of lipohypertrophy, as well
Key messages

- Men with HIV associated lipodystrophy may complain of low sexual desire

- There is a close correlation with low sexual desire and raised serum oestrogen levels in these men

- We postulate that the high oestrogen levels result from aromatisation of testosterone to oestrogen in lipogranulomas within the lipodystrophic tissue

- It is possible that aromatase antagonists, with or without testosterone, may help improve these symptoms

as an increased fibroblast and macrophage population in areas of lipoatrophy. Furthermore, there are good theoretical reasons why adipose cells, but not fibroblasts and macrophages, are lost in the lipoatrophy process. There is an increase in levels of TNF- $\alpha$ derived from CD4 and CD8 cells in patients on HAART, particularly those with lipodystrophy, ${ }^{39}$ which contributes to the apoptosis of adipose tissue. ${ }^{38}$ Relative sparing of blood vessels, fibroblasts, and macrophages in the lipogranulomatous area is probably the result of relative resistance of these cells to the apoptotic process. ${ }^{40}$ Receptors for type 2 TNF are also found at significantly high levels in patients with HIV lipodystrophy. ${ }^{18}$ Furthermore, TNF and hydroxycorticosteroids, which are known to be raised in HIV associated lipodystrophy are both known to markedly increase aromatase production in fibroblasts. ${ }^{281}$ We further postulate that fatty deposition in the neck and pharyngeal area of patients with HIV lipodystrophy may cause some degree of obstructive sleep apnoea, which in itself is known to increase and upregulate levels of IL-6 and TNF ${ }^{42}$ and hence aromatase production. ${ }^{28}$

We believe the above postulated mechanisms, at least in part, account for an increase in oestrogen levels in many men with HIV associated lipodystrophy. It is unclear how oestrogen decreases sexual desire but possibly this takes place by altering the sensitivity of hypothalamic areas to dopamine and serotonin. ${ }^{44}$

\section{TREATMENT OF LOW SEXUAL DESIRE IN PATIENTS WITH HIV LIPODYSTROPHY}

If, as we postulate, low desire in patients with HIV lipodystrophy is the result of the raised oestrogen levels, lowering these levels should tend to normalise their sexual dysfunction. Patients with epilepsy treated with antiepileptics, particularly phenytoin, have also been shown to have low testosterone and high oestradiol levels. ${ }^{45}$

Treatment of the epileptics with testosterone replacement versus testosterone plus an aromatase inhibitor (testolactone) resulted in similar testosterone levels in both treatment arms but significantly lower oestrogen levels and normalisation of sexual dysfunction and desire in the combination arm. ${ }^{45}$

There are now a number of aromatase inhibitors used to treat women with oestrogen sensitive metastatic carcinoma of the breast. These include formestene, anastrozole, and letrozole. They are all highly effective at inhibiting oestrogen production. In the short term letrozole appears to be well tolerated with no obvious toxicities, although a number of side effects may be apparent (for example, musculoskeletal pain, arthralgia, headache, fatigue, and nausea). However, it is difficult to ascertain if these were the result of the breast cancer disease, the concomitant medications, the aromatase inhibitor itself, or a combination of all three processes. ${ }^{46} 47$

Further caution should be adopted when considering giving aromatase inhibitors to patients on HAART, as they may be largely metabolised through the hepatic cytochrome P450 system. Theoretically, tamoxifen, an oestrogen receptor antagonist, could be used to suppress SHBG and thereby increase gonadotrophins and therefore testosterone. In 
practice, at least in women with breast cancer, tamoxifen unfortunately appears to worsen rather than improve sexual functioning. ${ }^{48}$

Finally, although it would seem that therapeutic testosterone would markedly increase oestrogen levels by increasing the substrate burden, we have found that many patients given such treatment seem to develop enhanced sexual libido and wellbeing and, indeed, this is our current practice.

\section{CONTRIBUTORS}

DG, hypothesis generator, wrote original and revised draft of paper, sees lipodystrophy patients with sexual dysfunction; GS, read and altered manuscript, clinical lead for lipodystrophy patients; MK, read and altered manuscripts, jointly runs lipodystrophy clinic; HL, read and altered manuscript, sees lipodystrophy patients with sexual dysfunction; GF, read and altered manuscript, psychologist lipodystrophy clinic.

\section{Authors' affiliations}

D Goldmeier, G Scullard, M Kapembwa, H Lamba, G Frize, Jefferiss Wing, St Mary's Hospital, London W2 INY, UK

\section{REFERENCES}

1 Laumann EO, Paik A, Rosen RC. Sexual dysfunction in the United States. Prevalence and predictions. JAMA 1999;281:537-44.

2 Dupras A, Morisset R. Sexual dysfunction among HIV positive gay men. Sexual and Marital Therapy 1993:8:37-46.

3 Laumann EO, Gagnon JH, Michael RT, et al. The social organisation of sexuality: sexual practices in the United States. Chicago: University of Chicago Press, 1994

4 Tindall B, Forde S, Goldstein D, et al. Sexual dysfunction in advanced HIV disease. AIDS Care 1994;6:105-7.

5 Newsham G, Taylor B, Gold R. Sexual functioning in ambulatory men with HIV/AIDS. Int J STD AIDS 1998;9:672-6.

6 Hofbauer LC, Heufelder AE. Endocrine implications of human immunodeficiency. virus infection. Medicine 1996;75:262-78.

7 Gluck T, Degenhardt E, Scholmerich J, et al. Autonomic neuropathy in patients with HIV: course, impact of disease stage and medication. Clin Autonom Res 2000;10:17-22

8 Rogstad KE, Shah R, Tesfaladet G, et al. Cardiovascular autonomic neuropathy in HIV infected patients. Sex Transm Inf 1999:75:264-7.

9 Becker K, Gorlach I, Frieling T, et al. Characterisation and natural course of cardiac autonomic nervous dysfunction in HIV infected patients. AIDS 1997;11:751-7.

10 Siddiqi NA, Shaikh RN, Ali ST. Assessment of neuropathic factor in HIV associated impotence: penile electrodiagnosis. Acta Physiol Hung 1996:84:73-80.

11 Ali ST, Shaikh RN, Siddiqi A. HIV 1 associated neuropathies in males: impotence and penile electrodiagnosis. Acta Neurol Belg 1994;94: 194-9.

12 Bancroft J. Human sexuality and its problems. Edinburgh: Churchill Livingstone, 1989.

13 Schrooten W, Colebunders R, Youle M, et al. Sexual dysfunction associated with protease inhibitor containing highly active retroviral treatment. AIDS 2001;15:1019-23.

14 Colebunders $\mathbf{R}$, Smets E, Verdonck K, et al. Sexual dysfunction with protease inhibitors. Lancet 1999;353:1802.

15 Martinez E, Collazos J, Mayo J, et al. Sexual dysfunction with protease inhibitors. Lancet 1999;353:810-11.

16 Behrens GM, Stoll M, Schimdt RE. Lipodystrophy syndrome in HIV infection: what is it, what causes it and how can it be managed. Drug Safety 2000;23:57-76.

17 Graham NM. Metabolic disorder among HIV infected patients treated with protease inhibitors - a review. J Acquir Immune Defic Syndr 2000;Suppl 1:S4-11.

18 Mynarcik DC, McNurlan MA, Steigbigel RT, et al. Association of severe insulin resistance with both loss of limb fat and elevated tumour necrosis factor receptor levels in HIV lipodystrophy. J Acquir Immune Defic Syndr 2000;25:312-21.

19 Benson JO, McGhee K, Coplan K, et al. Fat redistribution in indinavir treated patients with HIV infection. A review of post-marketing cases. $J$ Acquir Immune Defic Syndr 2000;25: 130-9.

20 Martinez E, Mocroft A, Garcia-Viejo MA, et al. Risk of lipodystrophy in HIV 1 infected patients treated with protease inhibitors: a prospective cohort study. Lancet 2001;357:592-8.
21 Van der Valk $M$, Gisolf EH, Reiss $P$, et al. Increased risk of lipodystrophy when nucleoside analogue reverse transcriptase inhibitors are included with protease inhibitors in the treatment of HIV infection. AIDS $2001 ; 15: 847-55$.

22 Lichenstein KA, Ward DJ, Moorman AC, et al. Clinical assessment of HIV-associated lipodystrophy in an ambulatory population. AIDS 2001;15:1389-98

23 Rink JD, Simpson ER, Barnard J, et al. Cellular characterisation of adipose tissue from various body sites in women. J Clin Endocrinol Metab 1996;81:2443-7.

24 Ackerman GE, Smith ME, Mendelson CR, et al. Aromatisation of androstenedione by human adipose tissue stromal cells in monlayer culture. J Clin Endocrinol Metab 1981;53:412-17.

25 Schmidt M, Kreutz M, Loffler G, et al. Conversion of dihydro-epiandrosterone to downstream steroid hormones in macrophages. J Endocrinol 2000;164:161-9.

26 Siiteri PK, Williams JE, Takaki NK. Steroid abnormalities in endometrial and breast carcinoma: a unifying hypothesis. J Steroid Biochem 1976;7:897-903

27 Bulun SE, Noble LS, Takayama K, et al. Endocrine disorders associated with inappropriately high aromatase expression. J Steroid Biochem Mol Biol 1997;61:133-9.

28 Singh A, Purohit A, Ghilchik MW, et al. The regulation of aromatase activity in breast fibroblasts; the role of interleukin 6 and prostaglandin E2. Endocrine Related Cancer 1999;6:139-47.

29 Zhao Y, Nichols JE, Bulun SE, et al. Aromatase P450 gene expression in human adipose tissue. Role of a Jak/STAT pathway in regulation of the adipose specific promotor. J Biol Chem 1995;270:16449-57.

30 Bujalska IJ, Kumar S, Stewart PM. Does central obesity reflect "Cushing's disese of the omentum." Lancet 1997;349:1210-13.

31 Joyner JM, Hutley L, Cameron DP. Glucocorticoid receptors in human pre-adipocytes: regional and gender difference. J Endocrinol 2000;166:145-52

32 McTeman PG, Anwar A, Eggo MC, et al. Gender differences in the regulation of P450 aromatase expression and activity in human adipose tissue. Int J Obesity Related Metab Disorders 2000;24:875-81.

33 Rietschel P, Corcoran C, Stanley T, et al. Prevalence of hypogonadism among men with weight loss related to human immunodeficiency virus infection who were receiving highly active antiretroviral therapy. Clin Infect Dis 2000:31:1240-4.

34 Taxel P, Kennedy D, Fall P, et al. The effect of short-term treatment with micronized estradiol on bone turnover and gonadotrophin in older men. Endocr Res 2000;26:381-98.

35 Pugeat M, Crave JC, Tourniaire J, et al. Clinical utility of sex hormone binding globulin measurement. Hormone Res 1996;45:148-55.

36 Phillips GB. Evidence for hyperoestrogenaemia as a risk factor for myocardial infarction in men. Lancet 1976;2:14-18.

37 Knussman R, Christiansen K, Couwenbergs C. Relations between sex hormone levels and sexual behaviour in men. Arch Sex Behav 1986; 15:429-45.

38 Domingo P, Matias-Guiu X, Pujol RM. Subcutaneous adipocyte apoptosis in HIV-1 protease inhibitor associated lipodystrophy. AIDS 1999:13:2261-7.

39 Ledru E, Christeff N, Patey O, et al. Alteration of tumour necrosis factor-alpha T cell haemostasis following potent antiretroviral therapy: contribution to the development of human immunodeficiency associated lipodystrophy syndrome. Blood 2000;95:3191-8.

40 Zhang XD, Nguyen T, Thomas WD, et al. Mechanisms of resistance of normal cells to TRAIL induced apoptosis vary between different cell types. FEBS Lett. 2000;482:193-9.

41 Yanovski JA, Miller KD, Kino T, et al. Endocrine and metabolic evaluation of human immunodeficiency virus infected patients with evidence of protease inhibition associated lipodystrophy. J Clin Endocrinol Metab 1999:84:1925-31.

42 Liu H, Liu J, Xiong S, et al. The change of interleukin 6 and tumour necrosis factor in patients with obstructive sleep apnoea. J Tongii Medical Univ 2000;20:200-2

43 Roytblat L, Rachinsky M, Fisher A, et al. Raised interleukin-6 levels in obese patients. Obesity Res 2000;8:673-5.

44 Baum MJ, Starr MS. Inhibition of sexual behaviour by dopamine antagonists or serotonin agonist drugs in castrated male rates given estradiol or dihydrotestosterone. Pharmacol Biochem I Rev 1987; 13:47-67.

45 Herzog AG, Klein P, Jacobs AR. Testosterone versus testosterone and testolactone in treating reproductive and sexual dysfunction in men with epilepsy and hypogonadism. Neurology 1998;50:782-4.

46 Lipton A, Demers LM, Harvey HA, et al. Letrozole (CGS 20267). A phase 1 study of a new potent oral aromatase inhibitor of breast cancer Cancer 1995;75:2132-8.

47 Michaud LB, Buzdar AU. Risks and benefits of aromatase inhibitors in post- menopausal breast cancer. Drug Safety 1999;21:297-309.

48 Mortimer J E, Boucher L, Baty J, et al. Effect of tamoxifen on sexual functioning in patients with breast cancer. J Clin Oncol 1999; 17:1488-92. 